\title{
Accurate detection of the tumor clone in peripheral T-cell lymphoma biopsies by flow cytometric analysis of TCR-V $\beta$ repertoire
}

\author{
Dimitri Salameire ${ }^{1,2,3,8}$, Françoise Solly ${ }^{1,2,3,8}$, Blandine Fabre ${ }^{2,3}$, Christine Lefebvre ${ }^{2,3}$, \\ Martine Chauvet ${ }^{2,3}$, Rémy Gressin ${ }^{2,3}$, Bernadette Corront ${ }^{4}$, Agnès Ciapa ${ }^{5}$, \\ Martine Pernollet ${ }^{2,3}$, Joël Plumas ${ }^{1,2,6}$, Elizabeth Macintyre ${ }^{7}$, Mary B Callanan ${ }^{1,2,3}$, \\ Dominique Leroux ${ }^{1,2,3}$ and Marie-Christine Jacob ${ }^{2,3}$
}

\begin{abstract}
${ }^{1}$ Université Joseph Fourier Grenoble 1, Grenoble, France; ${ }^{2}$ Inserm U823 Team 7 and 9, Laboratoire d'Immunologie,CRI/Institut Albert Bonniot, Université Joseph Fourier Grenoble 1, Grenoble, France; ${ }^{3} \mathrm{CHU}$ Albert Michallon, Departments of Immunology, Pathology, Hematology and Oncogenetic, Grenoble, France; ${ }^{4}$ Department of Hematology, CH de la région d'Annecy, Pringy, France; ${ }^{5}$ Histopathology Laboratory, Grenoble, France; ${ }^{6}$ RqD Department, Etablissement Français du Sang Rhône-Alpes, La Tronche, France and ${ }^{7}$ Department of Hematology, Necker-Enfants Malades, Paris, France
\end{abstract}

\begin{abstract}
Multiparametric flow cytometry has proven to be a powerful method for detection and immunophenotypic characterization of clonal subsets, particularly in lymphoproliferative disorders of the B-cell lineage. Although in theory promising, this approach has not been comparably fulfilled in mature T-cell malignancies. Specifically, the T-cell receptor- $\mathrm{V} \beta$ repertoire analysis in blood can provide strong evidence of clonality, particularly when a single expanded $V B$ family is detected. The purpose of this study was to determine the relevance of this approach when applied to biopsies, at the site of tumor involvement. To this end, 30 peripheral T-cell lymphoma and 94 control biopsies were prospectively studied. $\mathrm{V} \beta$ expansions were commonly detected within CD4 + or CD8 + T cells ( $97 \%$ of peripheral T-cell lymphoma and $54 \%$ of non-peripheral T-cell lymphoma cases); thus, not differentiating malignant from reactive processes. Interestingly, we demonstrated that using a standardized evaluation, the detection of a high $\mathrm{V} \beta$ expansion was closely associated with diagnosis of peripheral $\mathrm{T}$-cell lymphoma, with remarkable specificity $(98 \%)$ and sensitivity $(90 \%)$. This approach also identified eight cases of peripheral T-cell lymphoma that were not detectable by other forms of immunophenotyping. Moreover, focusing $\mathrm{V} \beta$ expression analysis to $\mathrm{T}$-cell subsets with aberrant immunophenotypes, we demonstrated that the T-cell clone might be heterogeneous with regard to surface $C D 7$ or $C D 10$ expression (4/11 cases), providing indication on 'phenotypic plasticity'. Finally, among the wide variety of $V \beta$ families, the occurrence of a $V \beta 17$ expansion in five cases was striking. To our knowledge, this is the first report demonstrating the power of T-cell receptor-V $\beta$ repertoire analysis by flow cytometry in biopsies as a basis for peripheral T-cell lymphoma diagnosis and precise T-cell clone identification and characterization.

Modern Pathology (2012) 25, 1246-1257; doi:10.1038/modpathol.2012.74; published online 25 May 2012
\end{abstract}

Keywords: flow cytometry; immunophenotype; T-cell clonality; T-cell lymphoma; TCR-V $\beta$ repertoire

Peripheral T-cell lymphomas are hematological malignancies that are thought to develop from

Correspondence: MC Jacob, Inserm U823 Team 7 and 9, Laboratoire d'Immunologie, CRI/Institut Albert Bonniot, Université Joseph Fourier Grenoble 1, Grenoble 38000, France. E-mail: MCJacob@chu-grenoble.fr

${ }^{8}$ These authors contributed equally to this work.

Received 09 November 2011; revised 23 February 2012; accepted 24 February 2012; published online 25 May 2012 transformed lymphocytes of post-thymic origin. These disorders account for about $10 \%$ of all nonHodgkin's lymphomas in Western countries. ${ }^{1,2}$ Their diagnosis relies on clinical, morphological and immunohistochemical evaluation. However, since none of these criteria are disease-specific, peripheral T-cell lymphoma diagnosis remains challenging, as evidenced by a large multicentric study where misclassification occurred in $10.4 \%$ of peripheral T-cell lymphoma cases. ${ }^{3}$ Therefore, complementary 
methods such as the assessment of T-cell clonality are generally required. Molecular techniques aiming at identifying monoclonal rearrangements of the gene loci of the T-cell receptor (TCR) $\gamma$ or $\beta$ chains are the gold standard, ${ }^{4-6}$ revealing the presence of a T-cell clone in 60-100\% of peripheral T-cell lymphomas $^{7-10}$ with good specificity, albeit not $100 \% .^{10}$ Although very useful in routine diagnosis, molecular assays are not quantitative, and do not allow the immunological characterization of the T-cell clone, which is a requisite for improving our knowledge of the malignant $\mathrm{T}$ cells involved in peripheral T-cell lymphomas.

In this setting, TCR repertoire analysis by flow cytometry offers significant opportunities, since it allows assessment of T-cell clonality, as well as immunophenotyping of malignant cells and quantification of tumor burden. ${ }^{11}$ Current immunophenotyping panels include a total of 25 monoclonal antibodies directed against epitopes of the variable region of the TCR- $\beta$ chain (Vß), covering about $70 \%$ of the T-cell repertoire according to the manufacturer. This technique has proved useful in detecting malignant $\mathrm{T}$ cells in peripheral blood samples from patients with diverse mature T-cell leukemias. ${ }^{11-16}$ T-cell clones use the same Vß domain, and are thus detected by an overexpressed VB family (direct identification) or by a restricted VB repertoire if they are not recognized by the 25 anti-Vß antibodies of the panel (indirect identification). However, T-cell clone analysis in blood samples is not optimal for peripheral T-cell lymphomas, as (1) there may be no circulating lymphoma cells, (2) malignant circulating cells may not precisely reflect the clone at the site of tumor involvement and (3) when present, clonal subsets are not always malignant, as observed in infectious or autoimmune conditions, as well as in elderly people. ${ }^{17-20}$ It should be noted that the applicability of the TCR-VB repertoire analysis in various biopsy samples has already been reported by several groups including ours. ${ }^{21}$ What remains unknown is the capacity of this approach to detect malignant T cells in peripheral organs and its power to differentiate malignant from reactive Vß expansions, which are expected to be frequent at the site of immune reactions. To answer this question, we prospectively examined a total of 30 biopsies involved by peripheral T-cell lymphomas and 94 lymphoid tissues not involved by T-cell lymphomas as control biopsies.

Immunophenotyping is part of the routine diagnosis of lymphomas as recommended by the 2008 WHO classification, ${ }^{22}$ and is commonly performed using immunohistochemical techniques. Pan-T-cellassociated antigens such as CD2, CD3, CD7 and CD5 are important in confirming the T-cell origin of a suspect population. Demonstration of the loss of one or more of these antigens can also be used as a surrogate marker for T-cell clonality, as opposed to the complete phenotype of normal T-lymphocytes. It is worth noting that it is neither constant nor completely tumor-specific. ${ }^{23-26}$ As their normal counterparts, T-cell clones belong to one of the $\mathrm{CD} 4+, \mathrm{CD} 8+$ and more rarely CD4-CD8- or CD4 $+\mathrm{CD} 8+$ subsets. However, this may be difficult to determine, especially in the case of minor tumor involvement. As flow cytometry has proven to be efficient in peripheral T-cell lymphoma immunophenotyping, we aimed at determining the relevance of TCR-VB repertoire analysis for the characterization of the T-cell clone.

\section{Materials and methods}

\section{Patients and Biopsy Samples}

We conducted a prospective study from November 2000 to August 2010 at Grenoble University Hospital. Patients provided informed consent, according to the protocol approved by the Institutional Review Board. Surgical biopsies were obtained from patients with suspicion of lymphoma. A single biopsy was used for morphological, flow cytometry, cytogenetic and molecular studies, according to the standard institutional protocol. ${ }^{21}$ A total of 124 biopsies fulfilling the following criteria were included: (i) at least 5 million cells recoverable for analysis, (ii) more than $80 \%$ viable cells, (iii) expression of the TCR $\alpha \beta / \mathrm{CD} 3$ complex on T-cell membrane and (iv) more than $25 \%$ CD3 + cells in the whole population. The biopsy sites were lymph nodes $(n=118)$, tonsil $(n=2)$, orbit $(n=1)$, spleen $(n=2)$ or skin $(n=1)$. Biopsies were collected from 124 patients aged $7-87$ years (median 51 ). The male to female ratio was $1.61: 1$.

\section{Histopathology}

In all, 30 biopsies from 30 patients were diagnosed as peripheral T-cell lymphomas using histology and immunohistochemical evaluation according to the 2008 WHO classification of hematological malignancies. ${ }^{22}$ They consisted of 13 peripheral T-cell lymphomas not otherwise specified, 14 angioimmunoblastic T-cell lymphomas, 1 Sezary syndrome, 1 adult T-cell leukemia/lymphoma and 1 T-cell prolymphocytic leukemia. The 94 remaining biopsies were controls. They were defined as lymphoid tissues not infiltrated with peripheral T-cell lymphomas, that is, with non-malignant resident $\mathrm{T}$ cells. They comprised 37 reactive hyperplasias, 27 Hodgkin's lymphomas, 23 B-cell lymphomas, 6 adenocarcinomas and 1 Castleman disease. In total, 81 cases had been reported previously. ${ }^{21}$

\section{Immunophenotyping and TCR-V $\beta$ Repertoire Analysis by Flow Cytometry}

Biopsies were processed during the first $48 \mathrm{~h}$ after surgical excision as described previously. ${ }^{21}$ Four-color immunostaining was performed using 
standard techniques, and analyses were conducted with a FACScalibur and CellQuest-Pro software (BD Biosciences, San Jose, CA, USA). The panel of monoclonal antibodies routinely used to detect and classify T-lymphoid malignancies was as follows: PE-Cy5-CD3 (UCHT1), FITC-CD4 (13B8.2), PE-CD8 (B9.11) and PE-CD10 (ALB1) from Beckman Coulter (Brea, CA, USA), and PE-CD7 (M-T701), FITC-CD2 (RPA-2.10) and FITC-CD5 (UCHT2) from BD Biosciences. This panel allows appreciation of the proportion of T-cell subsets in the biopsies and detection of immunophenotypic abnormalities, that is, loss of a pan-T-cell antigen (considered aberrant when the proportion of negative $\mathrm{T}$ cells exceeded $3 \%$ of total lymphocytes for CD3, or $15 \%$ for CD2, CD5 or CD7), or CD10 expression (considered abnormal when positive T-cell accounted for more than $5 \%$ of total lymphocytes). These criteria were based on our experience in phenotyping control biopsies. Such characteristics were further used to focus the TCR $-\mathrm{V} \beta$ repertoire analysis on a particular T-cell subset.

The TCR-V $\beta$ repertoire was analyzed using 25 monoclonal antibodies directed against the variable (V) region of the TCR- $\beta$ chain, including $24 \mathrm{VB}$ families from the IOTest Beta Mark kit (Beckman Coulter) and VB6.7 (Endogen, Woburn, MA, USA), as reported previously. ${ }^{21}$ PE-Cy7-CD4 (SFCI2TD11) and APC-CD8 (B9.11) from Beckman Coulter were combined with $\mathrm{V} \beta$ monoclonal antibodies to study the TCR repertoire of the so defined T-cell subsets in a single experiment. For peripheral T-cell lymphomas, other gating monoclonal antibodies were used, according to the particular T-cell clone phenotype: PE-Cy7-CD4 and APC-CD7 (CD7.6B7; CliniScience, Montrouge, France) when a defect in CD7 expression was demonstrated $(n=8)$, PE-Cy7-CD4 and APC-CD10 (H10a, BD Biosciences) when CD10 was positive on T cells $(n=1)$ and PE-Cy7-CD3 (UCHT1, Beckman Coulter) when the T-cell clone expressed neither CD4 nor CD8 $(n=2)$.

On the basis of our previous work assessing reference values for $\mathrm{V} \beta$ families in $\mathrm{CD} 4+$ and CD8 + T-cell populations in lymph nodes, ${ }^{21}$ T-cell expansions were defined as follows: (i) $\mathrm{V} \beta$ percentage over the mean $+3 \mathrm{~s} . d$. reference value within the corresponding T-cell subset (ie, CD4 + or CD8 + ), or (ii) sum of all $25 \mathrm{~V} \beta$ percentages below the mean -3 s.d. reference value in the corresponding T-cell subset (ie, 54\% in CD4 + and 41\% in CD8 + T cells). In the latter cases, expansions were not recognized directly by the monoclonal antibodies from the panel and were therefore referred to as 'out of panel' Vß expansions. For V $\beta$ expansions assessed within the 'double-negative' CD3 + CD4-CD8T-cell subset, the same reference values as for CD4 + T cells were used. In an effort to standardize the level of $\mathrm{V} \beta$ expansion, we calculated a ratio $(\mathrm{V} \beta$ ratio) between the observed VB percentage and the upper reference value (ie, mean +3 s.d.) of the corresponding family.

\section{Cytogenetic and Molecular Cytogenetic Analyses}

Cytogenetic analysis was performed on the same cell suspensions as were used for flow cytometry analysis, following $17 \mathrm{~h}$ unstimulated culture and a colchicine block. R-banded metaphase chromosomes were prepared by standard procedures. ${ }^{27}$

\section{Multiplex PCR Amplification and PCR Product Analysis}

Genomic DNA was isolated from frozen tissue biopsies using standard procedures. ${ }^{27}$ Detection of clonal $T C R \gamma$ gene rearrangements was performed using two techniques: (1) genomic DNA was submitted to a single multiplex polymerase chain reaction (PCR) using GC-clamp primers and analyzed by denaturing gradient gel electrophoresis, as described by Theodorou et al. ${ }^{4}$ (2) Samples were submitted to $T C R \gamma$ gene rearrangement amplification followed by Genescan analysis as described previously. ${ }^{28}$

\section{Results}

In all, 30 patients with peripheral T-cell lymphomas were prospectively included in this study. The details of clinical, histological, immunological, cytogenetic and molecular analyses are summarized in Table 1.

\section{VB Expansions are Observed in Both Peripheral T-Cell Lymphomas and Control Biopsies}

$\mathrm{V} \beta$ expansions were assessed within the CD4 + and CD8 + T-cell subsets, except for double-negative peripheral T-cell lymphoma cases for which they were evaluated within CD3 + cells. An expansion of at least one $\mathrm{V} \beta$ family was directly recognized by one of the 25 monoclonal antibodies from the panel in 29/30 peripheral T-cell lymphomas (97\%) and $51 / 94$ control cases (54\%). Additional V $\beta$ expansions were indirectly identified in peripheral T-cell lymphoma cases only $(5 / 30,17 \%)$ (Supplementary Data 1). Of note, Vß expansion within CD $4+$ T cells was unique in 20/27 peripheral T-cell lymphomas (74\%) vs 18/94 control cases (19\%). In contrast, 8/21 peripheral T-cell lymphomas (38\%) and 23/94 control cases $(24 \%)$ displayed this characteristic within CD8 + T cells. The expansion was unique in all three double-negative cases. When multiple in biopsies, $\mathrm{V} \beta$ expansions ranged from 2 to 6 within the CD $4+$ subset, and from 2 to 5 within CD8 + T cells.

Because of their high frequency in control biopsies, the presence of a $\mathrm{V} \beta$ expansion, whether single or multiple, was thus not sufficient to distinguish T-cell lymphomas from non T-cell lymphoma lesions. 
Table 1 Multidisciplinary characteristics of patients with T-cell lymphomas and control patients demonstrating a single high Vß expansion

\begin{tabular}{|c|c|c|c|c|c|c|c|c|c|c|c|}
\hline Patient & Gender & $\begin{array}{c}\text { Age } \\
\text { (years) }\end{array}$ & Histology & $\begin{array}{l}\text { Immunophenotypic } \\
\text { abnormalities } \\
\text { by FC }\end{array}$ & $\begin{array}{c}\text { TCR } \gamma \\
\text { rearrangement } \\
\text { PCR DGGE } \\
\text { (number of } \\
\text { bands) }\end{array}$ & Karyotype & $\begin{array}{l}\text { Staging at } \\
\text { presentation }\end{array}$ & Involved sites at presentation & B symptoms & $\begin{array}{l}\text { Autoimmunity } \\
\text { skin rash }\end{array}$ & $\begin{array}{l}\text { Follow-up } \\
\text { (months) }\end{array}$ \\
\hline
\end{tabular}

\begin{tabular}{|c|c|c|c|c|c|c|c|c|c|c|c|c|}
\hline 1 & $\mathrm{M}$ & 54 & PTCL-nos & None & C & A & IV & PolyADN+SP+BM & Yes & No & 10 & Died of disease \\
\hline 2 & $\mathrm{~F}$ & 38 & PTCL-nos & In CD4+:CD7- & $\mathrm{C}$ & A & IV & PolyADN+SP+BM & Yes & No & 108 & Relapse \\
\hline 3 & M & 65 & AITL & None & ND & ND & IV & PolyADN+SP+BM & Yes & AIHA & 3 & Died of disease \\
\hline 4 & M & 74 & AITL & In CD4+:CD7-10+ & $\mathrm{C}$ & $\mathrm{N}$ & III & PolyADN & No & No & 11 & Complete remission \\
\hline 5 & $\mathrm{M}$ & 56 & ATLL & In CD4+:CD7- & ND & ND & IV & PolyADN+SP+skin+bone & Yes & No & 10 & Lost to follow-up \\
\hline 6 & M & 41 & AITL & In CD4+:CD7- & $\mathrm{C}$ & A & IV & PolyADN+SP & Yes & Skin rash & 6 & Died of disease \\
\hline 7 & $\mathrm{~F}$ & 74 & PTCL-nos & In CD4+:CD7-10+ & $\mathrm{C}$ & $\mathrm{N}$ & IV & PolyADN+SP+liver+skin+BM & Yes & Erythrodermy & - & Lost to follow-up \\
\hline 8 & $\mathrm{~F}$ & 65 & AITL & In CD4+:CD7-10+ & C & $\mathrm{N}$ & IV & PolyADN+SP & Yes & AIHA & - & Partial remission \\
\hline 9 & M & 74 & PTCL-nos & In CD4+:CD7- & ND & A & III & PolyADN & No & No & 7 & Lost to follow-up \\
\hline 10 & M & 63 & PLL & None & $\mathrm{C}$ & A & IV & PolyADN+SP+skin & Yes & Nno & 9 & Died of disease \\
\hline 11 & $\mathrm{M}$ & 77 & PTCL-nos & In CD4+:CD7-10+ & $\mathrm{C}$ & ND & III & PolyADN & Yes & AIHA & 1 & Died of disease \\
\hline 12 & $\mathrm{~F}$ & 57 & AITL & In CD4+:CD7-10+ & $\mathrm{C}$ & $\mathrm{N}$ & IV & PolyADN+SP+BM & Yes & ND & 13 & Relapse \\
\hline 13 & $\mathrm{~F}$ & 56 & Sezary & In CD4+:CD7- & C & A & IV & PolyADN+SP+liver+skin & Yes & Erythrodermy & 46 & Partial remission \\
\hline 14 & $\mathrm{M}$ & 76 & PTCL-nos & None & $\mathrm{C}$ & A & IV & PolyADN & ND & ND & nd & Lost to follow-up \\
\hline 15 & M & 65 & PTCL-nos & In CD3+4-8- :CD7- & C & A & III & PolyADN+SP+BM & Yes & No & 37 & Died of disease \\
\hline 16 & $\mathrm{M}$ & 57 & PTCL-nos & In CD3+4-8-:CD7- & $\mathrm{C}$ & $\mathrm{F}$ & IV & PolyADN+SP & Yes & Skin rash & 0 & Died of disease \\
\hline 17 & $\mathrm{~F}$ & 48 & AITL & In CD4+:CD7-10+ & ND & ND & IV & PolyADN+SP+liver & Yes & AIHA+skin rash & 2 & Ongoing evaluation \\
\hline 18 & $\mathrm{~F}$ & 47 & AITL & None & C & A & IV & PolyADN+SP+liver & Yes & Skin rash & 1 & Died of disease \\
\hline 19 & $\mathrm{M}$ & 84 & AITL & In CD4+:CD7- & $\mathrm{C}$ & A & IV & PolyADN+BM & Yes & AIHA & 3 & Died of disease \\
\hline 20 & M & 71 & AITL & None & ND & A & II & PolyADN & No & No & 5 & Ongoing evaluation \\
\hline 21 & $\mathrm{M}$ & 57 & AITL & In CD4+:CD7-10+ & C (2) & A & IV & PolyADN+SP+liver & Yes & ITP & 47 & Complete remission \\
\hline 22 & $\mathrm{~F}$ & 58 & AITL & None & C (2) & A & IV & PolyADN & Yes & AIHA & 72 & Died of AML \\
\hline 23 & $\mathrm{M}$ & 66 & AITL & In CD4+:CD7-10+ & $\mathrm{C}$ & A & IV & PolyADN+BM & Yes & CIC & 20 & Died of disease \\
\hline 24 & $\mathrm{~F}$ & 68 & PTCL-nos & In CD4+:CD7- & C & ND & IV & PolyADN+tumoral ascite & Yes & ND & 1 & Died of disease \\
\hline 25 & M & 69 & PTCL-nos & None & $\mathrm{C}$ & A & II & PolyADN & Yes & No & 8 & Partial remission \\
\hline 26 & $\mathrm{~F}$ & 79 & PTCL-nos & In CD4+:CD7- & $\mathrm{C}$ & A & III & PolyADN+SP+liver+BM & Yes & No & 1 & Died of disease \\
\hline 27 & M & 26 & PTCL-nos & In CD3+4-8-:CD7- & $\mathrm{C}$ & A & IV & PolyADN+BM+liver & Yes & No & 160 & Complete remission \\
\hline 28 & $\mathrm{~F}$ & 79 & AITL & None & $\mathrm{C}$ & $\mathrm{N}$ & IV & PolyADN+SP & Yes & ND & 25 & Lost to follow-up \\
\hline 29 & $\mathrm{~F}$ & 42 & AITL & None & $\mathrm{P}$ & A & IV & PolyADN+BM & Yes & No & 33 & Complete remission \\
\hline 30 & $\mathrm{~F}$ & 57 & PTCL-nos & None & $\mathrm{P}$ & $\mathrm{N}$ & IV & PolyADN+SP+liver+skin+orbi+BM & Yes & No & 6 & Died of disease \\
\hline 31 & M & 64 & $\mathrm{RH}$ & None & $\mathrm{O}(3)^{*}$ & A & - & Regional polyADN & No & Skin rash & 58 & Complete remission \\
\hline 32 & M & 68 & HL & In CD8+:CD7- & $\mathrm{O}(3)^{*}$ & $\mathrm{~F}$ & I & Unique tumor of orbit & No & No & 60 & Complete remission \\
\hline
\end{tabular}

$\mathrm{O}(3)^{*}$ : Clonal TCR $\gamma$ rearrangement in gene scanning $V f 1-5 y 1 / 2$

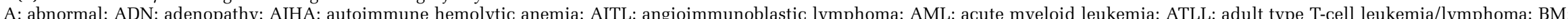

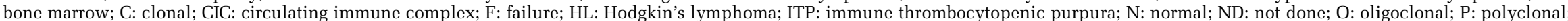
polyADN: poly-adenopathy; PLL: prolymphocytic leukemia; PTCL-nos: peripheral T-cell lymphoma, not otherwise specified; RH: reactive hyperplasia; SP: spleen. 


\section{The Extent of VB Expansions Differentiates Peripheral} T-Cell Lymphomas from Other Pathologies

As shown in representative cases of peripheral T-cell lymphomas and controls (Figure 1a), the amplitude of each $\mathrm{V} \beta$ family expansion was differ- ent among patients. Therefore, we subsequently investigated the diagnostic value of the size of individual $\mathrm{V} \beta$ expansions. As shown in a previous study, reference values established in lymphoid tissues were highly variable from one $\mathrm{V} \beta$ family to another. ${ }^{21}$ Thus, to compare accurately the degree of
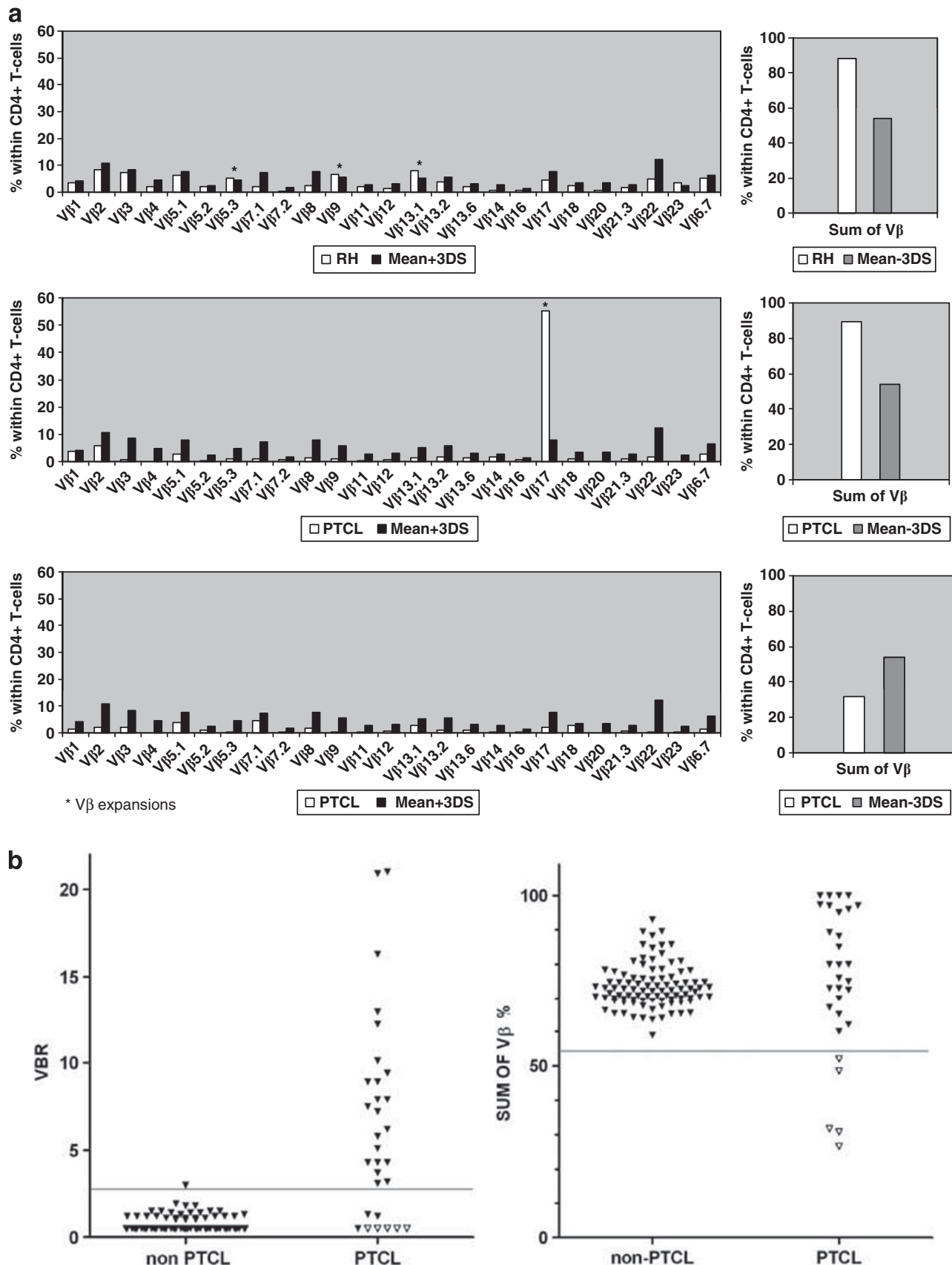

Figure 1 Sensitivity and specificity of the T-cell receptor (TCR)-V $\beta$ repertoire analysis for the diagnosis of peripheral T-cell lymphoma (PTCL) in biopsies. (a) Histogram representation of CD4 + TCR-V $\beta$ repertoire in representative cases from control (top) and PTCLs (middle and bottom). A polyclonal pattern with three $\mathrm{V} \beta$ low expansions $\left({ }^{*}\right)$ is shown in one case with reactive hyperplasia (RH). Monoclonal patterns with either a high $\mathrm{V} \beta$ expansion (middle) or an out of panel expansion (bottom) are illustrated in two cases with PTCL. In the latter case, the sum of $\mathrm{V} \beta$ is lower than the reference mean -3 s.d. value. (b) Left: The size of CD4 + or double-negative CD4-CD8- V $\beta$ expansions directly recognized by the monoclonal antibodies of the panel is represented by the $\mathrm{V} \beta$ ratio value (ratio between the V $\beta$ percentage and the upper reference value of the corresponding family). Using a V $\beta$ ratio cutoff value of 3 (gray line), 22/30 PTCL and 1/94 control patients demonstrated a high V $\beta$ expansion. (b) Right: The size of CD4 + or double-negative CD4-CD8- V $\beta$ expansions not directly recognized by the monoclonal antibodies of the panel is defined using the sum of all V $\beta$ percentages. A cutoff value of $54 \%$ (mean -3 s.d. of the reference value, gray line) isolated 5/30 PTCL and 0/94 control patients with an out of panel $\mathrm{V} \beta$ expansion, represented with empty triangles. 
expansions of individual $\mathrm{V} \beta$ families, we used a normalized ratio ( $\mathrm{V} \beta$ ratio) calculated between the observed $\mathrm{V} \beta$ percentage and the upper reference value of the corresponding family. ${ }^{21}$

As shown in Table $2, \mathrm{~V} \beta$ ratio ranged from 1 to 21 within CD4 $+\mathrm{T}$ cells, and from 1.1 to 6.5 within $\mathrm{CD} 8+\mathrm{T}$ cells. We graphically considered that a $\mathrm{V} \beta$ ratio cutoff value of three best separated patients with either high or low $\mathrm{V} \beta$ expansions (Figure 1b). Using this criterion, 23 cases displayed a high $\mathrm{V} \beta$ expansion within the CD4 + or the double-negative T-cell subsets. Of these, 22 cases $(96 \%)$ were peripheral T-cell lymphomas (mean $\mathrm{V} \beta$ ratio: 8.7; range: $3.1-21)$ and one case $(4 \%)$ was not (mean $\mathrm{V} \beta$ ratio: 3). The expansion was unique in all cases (Figure 1b). In the CD8 + subsets, all V $\beta$ expansions presented a $\mathrm{V} \beta$ ratio lower than 3 , except in three control cases $(3 / 94,3 \%)$. The expansion was unique in only one of them, a case of Hodgkin's lymphoma (patient 32, V $\beta$ ratio: 6.5). For all cases with high $\mathrm{V} \beta$ expansions, the proportion of the expanded $\mathrm{V} \beta$ family in total lymphocytes ranged from 4 to $82.8 \%$ (mean: $35.8 \%$ ).

Thus, a high and unique, 'in' or 'out of panel' V $\beta$ expansion was observed in 27/30 peripheral T-cell lymphomas $(90 \%)$, exclusively within CD4 + or double-negative $\mathrm{T}$ cells. In control biopsies, this occurred in only $2 / 94$ cases $(2 \%)$, within CD4 + as well as CD8 + T cells.

The three peripheral T-cell lymphoma cases with no or low $\mathrm{V} \beta$ expansions (patients 28-30) had been classified as peripheral T-cell lymphomas not otherwise specified (patient 30) or angioimmunoblastic T-cell lymphoma (patients 28 and 29). None demonstrated an aberrant immunophenotype (Table 1). Clonal TCR $\gamma$ rearrangements were detected in patient 28 , by both denaturating gradient gel electrophoresis and Genescan analyses, whereas a faint clonal rearrangement in a polyclonal background was identified only by Genescan in patient 29. In this latter case, a pseudotetraploid (91-95 chromosomes) 'chaotic' karyotype was observed (8/21 mitoses) and DNA content assessed by flow cytometry was near tetraploid in $5 \%$ of the cells (data not shown). In contrast, patient 30 did not show any clonal aberration either by flow cytometry, cytogenetic or molecular assays (Supplementary Data 2).

Quite strikingly, both control biopsies presenting a high and unique $\mathrm{V} \beta$ expansion within one of the CD4 + or CD8 + T-cell subsets were found to display clonal $T C R \gamma$ rearrangements using molecular techniques, thereby confirming the presence of a T-cell clone. Patient 31 was diagnosed with reactive hyperplasia in the context of EBV infection, confirmed by the detection of IgM EBNA antibodies and EBV PCR products. Patient 32 was diagnosed with T-lymphocyte-rich Hodgkin's lymphoma of the orbit. Loss of CD7 expression was observed on $\mathrm{CD} 8+\mathrm{T}$ cells. It is worth noting that karyotypic abnormalities were detected in both cases, albeit of nonspecific nature (Supplementary Data 2).
In summary, using a $\mathrm{V} \beta$ ratio threshold value of 3 , TCR-V $\beta$ repertoire analysis showed a sensitivity of $90 \%$ and a specificity of $98 \%$ for the diagnosis of peripheral T-cell lymphomas, and the T-cell clone could be identified as a specific $\mathrm{VB}$ expansion in $73 \%(22 / 30)$ of cases (Figure 1$)$.

\section{T-cell Clones can be Heterogeneous with Respect to T-Cell Antigens or CD10 Expression}

As shown in Table 1, 19/30 peripheral T-cell lymphoma cases (63\%) exhibited aberrant cell surface molecule expression patterns by flow cytometry. CD7 expression was absent in 19/30 (63\%) of cases and CD10 was present in $8 / 30(27 \%)$. In addition, three TCR $\alpha \beta$-expressing cases demonstrated neither CD4 nor CD8 positivity.

Of note, VB expansions were not only detected, directly or indirectly, in all peripheral T-cell lymphoma cases with phenotypic aberrations, but also in eight cases with normal expression of lymphocyte markers.

Interestingly, in 11 lymph node biopsies (Table 3), we could focus TCR-Vß repertoire analysis on particular T-cell subsets using specific gating antibodies: (i) CD4 and CD7 for eight cases in which the CD4 + lymphoma cells demonstrated a defect in CD7 expression; (ii) CD3 and CD7 for two CD4 and CD8 double-negative cases also presenting a CD7 - phenotype; or (iii) CD4 and CD10 for one case positive for CD10. As expected, the expanded VB family was selectively increased in the T-cell population presenting an aberrant phenotype compared with the whole CD4 + or CD3 + subsets. In four cases, the expanded Vß family was also overrepresented in T lymphocytes expressing a 'normal' phenotype, whereas in seven cases, its expression was within normal ranges (Figure 2).

\section{A Large Set of VB Families are Expressed in Peripheral T-Cell Lymphomas}

The T-cell clone was identified by one of the 25 monoclonal antibodies from the panel in 22/30 cases of peripheral T-cell lymphomas (73\%) (Table 2). A total of 14 different $\mathrm{V} \beta$ families were involved, most of them in one case or two cases each. Only VB3 and Vb17 were more frequently expressed, that is, in three and five cases, respectively. In the remaining five peripheral T-cell lymphoma cases $(17 \%)$, the T-cell clone could not be recognized by the monoclonal antibodies of the panel (Figure 3).

\section{Discussion}

In this prospective study on a large cohort of 124 patients (30 peripheral T-cell lymphomas, 94 control cases), we demonstrated for the first time that 
Table 2 Characteristics of T-cell subsets and V $\beta$ expansions in biopsies from peripheral T-cell lymphomas and from discordant control patients

\begin{tabular}{|c|c|c|c|c|c|c|c|c|c|c|c|c|}
\hline \multirow[t]{2}{*}{ Patient } & \multirow[t]{2}{*}{ Histology } & \multirow[t]{2}{*}{$\begin{array}{l}C D 3 \\
(\%)\end{array}$} & \multirow[t]{2}{*}{$\begin{array}{l}C D 4 \\
(\%)\end{array}$} & \multirow[t]{2}{*}{$\begin{array}{l}C D 8 \\
(\%)\end{array}$} & \multirow[t]{2}{*}{$\begin{array}{l}\text { Main VB } \\
\text { expanded }\end{array}$} & \multirow{2}{*}{$\begin{array}{l}\text { T-cell subset } \\
\text { with the } \\
\text { main VB } \\
\text { expansion }\end{array}$} & \multicolumn{3}{|c|}{$\begin{array}{c}\text { Size of VB expansion within T-cell } \\
\text { subsets (CD4+CD8+CD3+CD4-CD8-) }\end{array}$} & \multirow{2}{*}{$\begin{array}{c}\% \text { of } V B \\
\text { expansion in } \\
\text { total } \\
\text { lymphocytes }\end{array}$} & \multirow{2}{*}{$\begin{array}{c}\text { Other VB } \\
\text { expansions in } \\
\text { the } T-C D 4+ \\
\text { subset }(V B R)\end{array}$} & \multirow{2}{*}{$\begin{array}{c}\text { Other VB } \\
\text { expansions in } \\
\text { the } T-C D 8+ \\
\text { subset }(V B R)\end{array}$} \\
\hline & & & & & & & $V B(\%)$ & $\begin{array}{l}\text { Reference } \\
\text { value }(\%)^{\mathrm{a}}\end{array}$ & $V B R^{\mathrm{b}}$ & & & \\
\hline 1 & PTCL-nos & 92 & 81 & 11 & VB9 & CD4 & 70.6 & $<7.93$ & 8.9 & 61.4 & - & VB7.2 (1.4) \\
\hline 2 & PTCL-nos & 90 & 75 & 11 & Vß13.1 & CD4 & 31.0 & $<6.87$ & 5.1 & 26.1 & - & Vß11 (1.2) Vß16 (1.5) \\
\hline 3 & AITL & 60 & 30 & 27 & Vß4 & $\mathrm{CD} 4$ & 43.2 & $<4.27$ & 10.1 & 24.6 & - & - \\
\hline 4 & AITL & 93 & 81 & 14 & Vß17 & $\mathrm{CD} 4$ & 67.7 & $<9.42$ & 7.2 & 54.8 & - & ND \\
\hline 5 & ATLL & 78 & 59 & & VB13.2 & $\mathrm{CD} 4$ & 78.0 & $<6.06$ & 12.9 & 46.0 & - & ND \\
\hline 6 & PTCL-nos & 83 & 70 & 11 & VB7.2 & $\mathrm{CD} 4$ & 58.0 & $<2.76$ & 21.0 & 40.6 & - & VB5.2 (1.7) \\
\hline 7 & PTCL-nos & 90 & 73 & 12 & VB8 & CD4 & 77.2 & $<8.23$ & 9.4 & 56.4 & - & ND \\
\hline 8 & AITL & 70 & 58 & 17 & VB17 & CD4 & 40.9 & $<9.42$ & 4.3 & 23.7 & - & VB23 (1.2) \\
\hline 9 & PTCL-nos & 75 & 64 & 7 & VB5.1 & CD4 & 37.9 & $<11.9$ & 3.1 & 24.3 & - & $\mathrm{V} ß 1(1.2)$ \\
\hline 10 & PLL & 91 & 90 & 1 & VB20 & CD4 & 88.1 & $<5.4$ & 16.3 & 79.3 & - & Vß1 (1.9) Vß20(1.8) \\
\hline 11 & PTCL-nos & 68 & 47 & 18 & VB5.1 & CD4 & 73.5 & $<11.9$ & 6.2 & 34.5 & - & - \\
\hline 12 & AITL & 79 & 53 & 23 & VB7.1 & $\mathrm{CD} 4$ & 57.3 & $<4.7$ & 12.2 & 30.4 & - & ND \\
\hline 13 & Sezary & 98 & 92 & 2 & VB12 & $\mathrm{CD} 4$ & 90.0 & $<4.3$ & 20.9 & 82.8 & - & ND \\
\hline 14 & PTCL-nos & 83 & 74 & 8 & $\mathrm{~V} ß 2$ & $\mathrm{CD} 4$ & 75.0 & $<17.55$ & 4.3 & 55.5 & - & Vß4 (1.3) Vß18 (1.5) \\
\hline 15 & PTCL-nos & 70 & 16 & 5 & Vß3 & CD3+CD4-CD8- & 49.8 & $<11.47$ & 4.3 & 24.9 & ND & ND \\
\hline 16 & PTCL-nos & 59 & 12 & 19 & VB3 & CD3+CD4-CD8- & 37.2 & $<11.47$ & 3.2 & 21.9 & ND & ND \\
\hline 17 & AITL & 72 & 47 & 21 & Vß17 & CD4 & 71.0 & $<9.42$ & 7.5 & 10.0 & - & - \\
\hline 18 & AITL & 67 & 50 & 29 & Vß13.6 & $\mathrm{CD} 4$ & 37.0 & $<4,67$ & 7.9 & 19.0 & - & VB2 (1.2) \\
\hline 19 & AITL & 59 & 47 & 6 & Vß3 & CD4 & 30.0 & $<11.47$ & 7.9 & 27.0 & - & Vß2 (1.2) \\
\hline 20 & AITL & 34 & 17 & 13 & Vß13.1 & $\mathrm{CD} 4$ & 25.3 & $<6.87$ & 3.7 & 4.0 & - & VB4 (1) \\
\hline 21 & AITL & 55 & 44 & 14 & Vß17 & $\mathrm{CD} 4$ & 55.0 & $<9.42$ & 5.8 & 24.2 & - & VB12 (1.8) VB16 (1.3) VB6.7 (1.2) \\
\hline 22 & AITL & 85 & 75 & 3 & Vß17 & $\mathrm{CD} 4$ & 83.7 & $<9.42$ & 8.9 & 63.0 & - & VB8 (1) VB12 (2.3) \\
\hline 23 & AITL & 65 & 39 & 20 & OPVB & $\mathrm{CD} 4$ & $\Sigma \mathrm{Vb} \mathrm{CD} 4=31.8$ & $>54.18$ & - & - & - & Vß5.1 (1.1) Vß18(1.2) \\
\hline 24 & PTCL-nos & 70 & 61 & 11 & OPVB & CD4 & $\Sigma \mathrm{Vb}$ CD $4=48.5$ & $>54.18$ & - & - & - & ND \\
\hline 25 & PTCL-nos & 89 & 82 & 7 & OPVB & $\mathrm{CD} 4$ & $\Sigma \mathrm{VbCD} 4=26.6$ & $>54.18$ & - & - & - & Vß7.2(1.1) \\
\hline 26 & PTCL-nos & 65 & 49 & 20 & OPVB & $\mathrm{CD} 4$ & $\Sigma \mathrm{Vb} \mathrm{CD} 4=30.8$ & $>54.18$ & - & - & - & ND \\
\hline 27 & PTCL-nos & 90 & 23 & 33 & OPVB & CD3+CD4-CD8- & $\Sigma \mathrm{Vb} \mathrm{CD} 3=52$ & $>54.18$ & - & - & ND & ND \\
\hline 28 & AITL & 91 & 68 & 18 & None & - & - & - & - & - & VB7.1 (1.2) VB6.7 (1.2) & VB7.1 (1.6) VB6.7 (2.6) \\
\hline 29 & AITL & 85 & 76 & 6 & None & - & - & - & - & - & - & - \\
\hline 30 & PTCL-nos & 89 & 34 & 56 & None & - & - & - & - & - & Vß7.1 (1) Vß9 (1.3) & VB7.1 (1.2) VB9 (2.5) \\
\hline 31 & $\mathrm{RH}$ & 40 & 31 & 14 & VB17 & CD4 & 28.0 & $<9.42$ & 3.0 & 8.7 & - & $\begin{array}{l}\text { VB2 (1.3) VB4 (1.3) VB5.3 } \\
\text { (2.2) VB13.2 (3.6) VB20 (1.5) }\end{array}$ \\
\hline 32 & HL & 95 & 64 & 32 & VB13.1 & CD8 & 48.9 & $<7.57$ & 6.5 & 15.7 & - & - \\
\hline
\end{tabular}

${ }^{\mathrm{a}}$ Reference value: mean +3 s.d. for each $\mathrm{V} \beta$ family;

${ }^{\mathrm{b}} \mathrm{ND}$ : not done; OPV $\beta$ : out of panel $\mathrm{V} \beta$ expansion; $\Sigma \mathrm{Vb}$ : sum of all $\mathrm{V} \beta$; VBR: V $\beta$ ratio. 
Table 3 Immunophenotypical heterogeneity of the T-cell clone in peripheral T-cell lymphomas (11 cases)

\begin{tabular}{|c|c|c|c|}
\hline Patient & $V \beta$ expanded & $\begin{array}{l}V \beta \text { reference } \\
\text { values }(\%)\end{array}$ & Gate: $\% V \beta$ expansion \\
\hline 2 & $\mathrm{~V} \beta 13.1$ in $\mathrm{CD} 4$ & $<6.87$ & $\begin{array}{l}\text { CD4+: } 35 \\
\text { CD4+CD7+: } 29 \\
\text { CD4+CD7-: } 47\end{array}$ \\
\hline 4 & $\mathrm{~V} \beta 17$ in $\mathrm{CD} 4$ & $<9.42$ & $\begin{array}{l}\text { CD4+: } 68 \\
\text { CD4+CD7+: } 61 \\
\text { CD4+CD7-: } 88\end{array}$ \\
\hline 6 & $\mathrm{~V} \beta 7.2$ in CD 4 & $<2.76$ & $\begin{array}{l}\text { CD4+: } 58 \\
\text { CD4+CD7+: } 5.8 \\
\text { CD4+CD7-: } 89\end{array}$ \\
\hline 9 & $\mathrm{~V} \beta 5.1$ in CD4 & $<11.9$ & $\begin{array}{l}\text { CD4+: } 38 \\
\text { CD4+CD7+: } 6.3 \\
\text { CD4+CD7-: } 81\end{array}$ \\
\hline 12 & $\mathrm{~V} \beta 7.1$ in CD 4 & $<4.7$ & $\begin{array}{l}\text { CD4+: } 57 \\
\text { CD4+CD10-: } 32 \\
\text { CD4+CD10+: } 97\end{array}$ \\
\hline 16 & $\mathrm{~V} \beta 3$ in CD3+CD4-CD8- & $<11.47$ & $\begin{array}{l}\text { CD3+: } 37 \\
\text { CD3+CD7+: } 3.8 \\
\text { CD3+CD7-: } 85\end{array}$ \\
\hline 17 & $\mathrm{~V} \beta 17$ in $\mathrm{CD} 4$ & $<9.42$ & $\begin{array}{l}\text { CD4+: } 15 \\
\text { CD4+CD7+: } 5 \\
\text { CD4+CD7-: } 66\end{array}$ \\
\hline 19 & $\mathrm{~V} \beta 3$ in $\mathrm{CD} 4$ & $<11.47$ & $\begin{array}{l}\text { CD4+: } 30 \\
\text { CD4+CD7+: } 8 \\
\text { CD4+CD7-: } 90\end{array}$ \\
\hline 18 & $\mathrm{OP} \mathrm{V} \beta$ in $\mathrm{CD} 4$ & $>54.18$ & $\begin{array}{l}\text { CD4+: } 49 \\
\text { CD4+CD7+: } 65 \\
\text { CD4+CD7-: } 26\end{array}$ \\
\hline 20 & $\mathrm{OP} \mathrm{V} \beta$ in $\mathrm{CD} 4$ & $>54.18$ & $\begin{array}{l}\text { CD4+: } 31 \\
\text { CD4+CD7+: } 86 \\
\text { CD4+CD7-: } 13\end{array}$ \\
\hline 27 & $\mathrm{OP} V \beta$ in $\mathrm{CD} 3+\mathrm{CD} 4-\mathrm{CD} 8-$ & $>54.18$ & $\begin{array}{l}\text { CD3+: } 52 \\
\text { CD3+CD7+: } 66 \\
\text { CD3+CD7-: } 19\end{array}$ \\
\hline
\end{tabular}

OP: out of panel.
TCR-V $\beta$ repertoire analysis by flow cytometry represents a sensitive and specific tool to detect, identify and quantify malignant T-cell clones in lymphoid tissue biopsies.

We chose to investigate biopsies rather than blood samples since peripheral T-cell lymphoma cases exist with no leukemic involvement. Furthermore, analysis in biopsies is more adapted to unambiguous identification of the malignant T-cell clone since, as mentioned previously, clonal circulating $\mathrm{T}$ cells are frequently observed in non-malignant conditions, leading to potential confusion between reactive and tumor cells. ${ }^{17}$

On the basis of the promising results obtained from blood samples, ${ }^{11-16}$ we used flow cytometry to assess the expression of $25 \mathrm{~V} \beta$ chain members of the TCR. Indeed, T-cell clones use a single V $\beta$ domain and can thus be identified by the abnormal expansion of one $\mathrm{V} \beta$ family or by a restricted TCR-V $\beta$ repertoire (see Materials and methods). Using our previously reported criteria for defining $\mathrm{V} \beta$ expansions, ${ }^{21}$ clonal subsets were thus found in $97 \%$ of peripheral T-cell lymphomas and 54\% of control cases, and thus suggesting that this parameter is not suitable for distinguishing malignant and reactive processes, ${ }^{29-31}$ despite significant statistical differences. In contrast, we demonstrated that assessment of the magnitude of $\mathrm{V} \beta$ expansion by the calculation of a $\mathrm{V} \beta$ ratio is highly discriminative. ${ }^{21}$ Using a threshold value of 3 , the presence of a high $\mathrm{V} \beta$ expansion was found to be closely associated with a
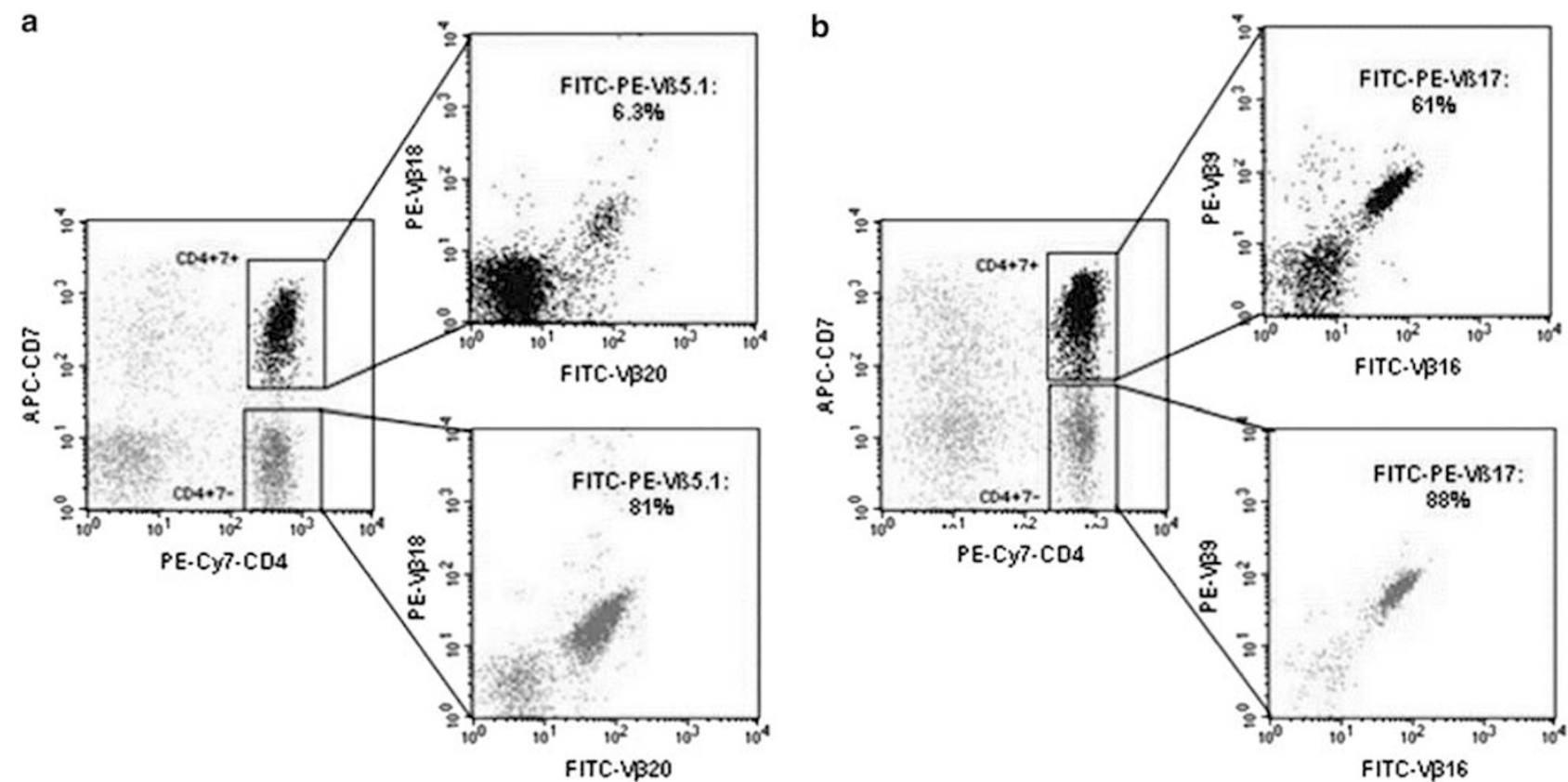

Figure 2 Simultaneous analysis of aberrant T-cell immunophenotype and Vßexpansion. Lymphocytes from patient 9 (a) and 4 (b) lymph nodes were stained with the anti-VB combination of the IOTest Beta Mark kit containing the previously identified expanded family (FITC-PE-Vß5.1 for patient 9 and FITC-PE-Vß17 for patient 4), in combination with PECy7-CD4 and APC-CD7 antibodies. CD4 + CD7 + and CD4 + CD7 - T cells were gated separately (a and b, left), and the frequency of the expanded V $\beta$ family was reported within each subset (a and $\mathbf{b}$, right). In patient 9, the expanded V $\beta$ family was mainly CD7-, whereas for patient 4, it consisted of both CD7- and CD7 + cells. 


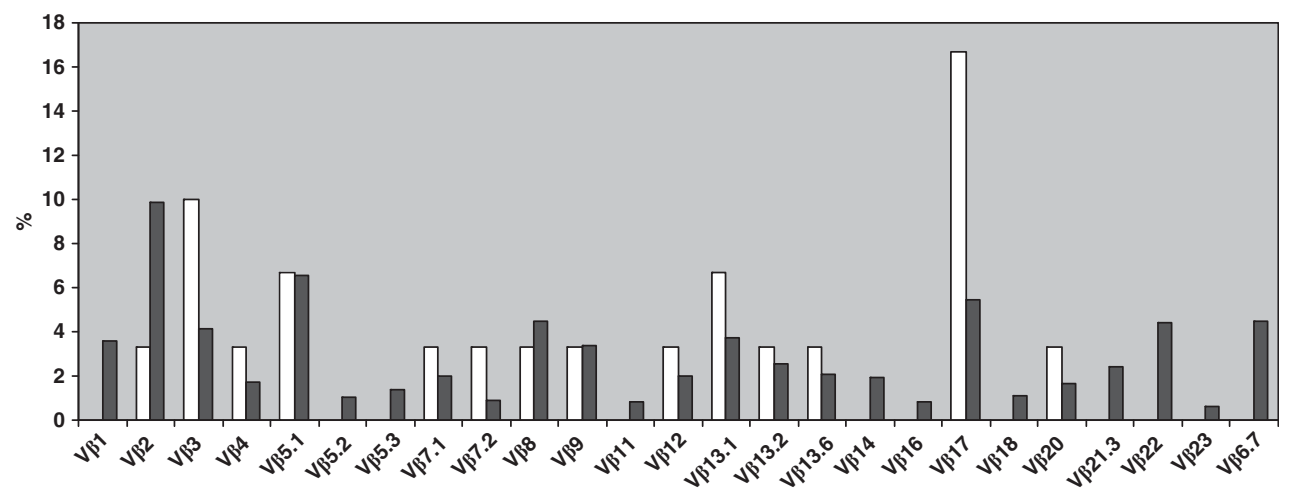

$\square$ Frequency of $\mathbf{V} \beta$ families in peripheral T-cell lymphoma $\square$ Mean frequency of $V \beta$ families in control biopsies

Figure 3 T-cell receptor (TCR)-V $\beta$ families involved in peripheral T-cell lymphomas. V $\beta 17$ and V $\beta 3$ are the most frequently expanded families in this series of 30 peripheral T-cell lymphomas.

diagnosis of peripheral T-cell lymphoma, with a remarkable specificity (98\%) and sensitivity (90\%).

By this method, false-positive results were observed in only 2 out of 94 control biopsies that demonstrated a high and unique $\mathrm{V} \beta$ expansion within CD4+ (patient 31) or CD8 + (patient 32) T-cell populations. These two false-positive cases most likely reflect true clonal expansions as monoclonal $T C R \gamma$ gene rearrangements and chromosomal aberrations were also detected. Of note, such characteristics do not necessarily imply the presence of a malignant disorder, as chromosomal abnormalities have also been demonstrated in a wide variety of benign tumors as well as in reactive processes. (Mitelman Database of Chromosome Aberrations and Gene Fusions in Cancer.) This raises the central question of the relationship between clonality and malignancy. Detection of non-malignant clonal T-cell populations has been widely reported in the literature in various settings, particularly within CD8 + T cells. ${ }^{17-20}$ The high specificity of the present approach with respect to peripheral T-cell lymphoma diagnosis might result from its application to biopsy samples rather than to peripheral blood, and from its ability to precisely measure the size of the clone ${ }^{11}$ which appears as an advantage over semiquantitative molecular methods. In the B-cell lineage, quantification of the clone is also a relevant parameter to distinguish some B-cell-derived disorders as myeloma or chronic lymphoid leukemia from non-malignant expansions, respectively, monoclonal gammopathy of undetermined significance and monoclonal $\mathrm{B}$ lymphocytosis. ${ }^{22}$

False-negative cases with no $\mathrm{V} \beta$ expansion despite the histological diagnosis of peripheral T-cell lymphoma were rare in our series (3/30). Two cases (patients 28 and 29) undoubtedly reflected technical limitations in the flow cytometry analysis as T-cell clones were detected by other techniques. In the third case (patient 30), clonality was not demonstrated in several biopsies whatever the technique used (TCR gene rearrangement, flow cytometry and karyotype). Whether this indicated the presence of a very minor clone or represented a false positive of histology could not be definitively judged by this analysis alone. This is in line with molecular reports of peripheral T-cell lymphoma cases without the identification of a T-cell clone, despite the use of sensitive methods. ${ }^{6}$ Because of the criteria employed with regard to the magnitude of $\mathrm{V} \beta$ expansions, TCR$\mathrm{V} \beta$ repertoire analysis by flow cytometry might only be able to detect large malignant populations, depending on the expanded $\mathrm{V} \beta$ family (three times the upper reference value of the $\mathrm{V} \beta$ family). ${ }^{21}$ Nevertheless, our results demonstrated that this limitation only marginally impacts on peripheral T-cell lymphoma diagnosis, as only 3/30 peripheral T-cell lymphoma cases were not detected in our series. The sensitivity of TCR-V $\beta$ repertoire analysis appears similar to what can be expected from molecular assays according to published studies, ${ }^{6,32}$ although this comparison implies data derived from different cohorts of patients.

Another approach for T-cell clonality relies on the detection of an aberrant immunophenotype, that is, absence of expression of a T-cell marker-CD2, CD3, CD5, CD7-or positivity for CD10 (75\% of peripheral T-cell lymphomas in our institution (data not shown), in accordance with the literature). ${ }^{23}$ In the present series of 30 peripheral T-cell lymphomas, CD3 - clones have been excluded because of the associated absence of TCR. They account for $35 \%$ of all peripheral T-cell lymphomas using flow cytometry analysis. Interestingly, we showed that high $\mathrm{V} \beta$ expansions were always associated with phenotypic abnormalities in biopsies, arguing that this criterion is very specific for the diagnosis of peripheral T-cell lymphomas. Furthermore, high $\mathrm{V} \beta$ expansions were also observed in eight biopsies without detectable membrane marker expression loss or CD10 expression, indicating that the TCR-V $\beta$ analysis increased the sensitivity of immunophenotypic diagnosis of peripheral T-cell lymphomas with expression of the 
CD3/TCR $\alpha \beta$ complex at the membrane. Hence, it is postulated that TCR-V $\beta$ repertoire analysis by flow cytometry could be regarded as a promising approach in the peripheral T-cell lymphoma diagnosis strategy.

Importantly, the demonstration that malignant T-cell clones could be unambiguously identified by one of the 25 anti-V $\beta$ monoclonal antibodies in $73 \%$ of peripheral T-cell lymphomas provides a powerful marker for more precise characterization of the tumour clone without confusion with reactive $\mathrm{T}$ cells. Such an approach proved to be very informative to phenotype T-cell clones using immunohistochemistry after $\mathrm{V} \beta$ identification by spectratyping. ${ }^{32}$ Interestingly, our strategy appears easier to perform and allows the simultaneous analysis of a larger set of markers. In our series, we thus determined that the T-cell clone belonged to the CD4 + subset or was double negative, but never $\mathrm{CD} 8+$. We also established that immunophenotypic aberrations may only partially involve the clonal population, as observed in 4 out of 11 cases showing a CD4 + CD7- or CD4-CD10 + phenotype. Such a result is not in favor of the hypothesis that peripheral T-cell lymphomas would arise from the expansion of a CD7- normal counterpart that underwent oncogenic transformation. It may rather reflect 'phenotypic plasticity'. Progressive downregulation of membrane protein expression has been described in Sezary's syndrome, ${ }^{33,34}$ and may play a role in the progression of T-cell lymphoma. ${ }^{35}$ Intraclonal heterogeneity is indeed a well-known phenomenon illustrated on karyotypic studies demonstrating variable additional genetic abnormalities within a single clone. (Mitelman Database of Chromosome Aberrations and Gene Fusions in Cancer.) These results outline that TCR-V $\beta$ repertoire analysis is a more precise approach to identify and characterize a T-cell clone than abnormal expression of T-cell markers. Such an observation is of great importance when aiming at differentiating malignant $\mathrm{T}$ cells from normal resident subsets.

Moreover, characterization of a malignant clone by its $\mathrm{V} \beta$ specificity is also a promising approach for disease monitoring. Indeed, a single tube including the appropriate $\mathrm{V} \beta$ can be used to assess tumor burden and treatment response in diverse sites such as blood, bone marrow or needle aspirates. ${ }^{36}$ Aberrant expression of T-cell markers by malignant $\mathrm{T}$ cells further allows for improved gating for $\mathrm{V} \beta$ clonality analysis, leading to increase detection sensitivity and specificity. ${ }^{12,37}$

In this series of 30 peripheral T-cell lymphomas, a wide variety of $\mathrm{V} \beta$ families was involved (14 out of 25 specific and 5 out of panel families). They were observed at low frequencies, except $\mathrm{V} \beta 17$ that appeared to be expanded in 5/30 cases (Figure 3). Of note, all five V $\beta 17$ peripheral T-cell lymphomas were classified as angioimmunoblastic T-cell lymphoma. Moreover, the EBV-infected case (patient 31) also demonstrated a high V $\beta 17$ expansion.
Considering the known association between EBV and angioimmunoblastic T-cell lymphoma, ${ }^{37}$ its role as a common antigen or superantigen in the pathogenesis of this peripheral T-cell lymphoma subtype could be hypothesized. In addition, preferential use of some $\mathrm{V} \beta$ families has been reported in leukemic phase of cutaneous T-cell lymphoma ${ }^{16}$ and T-CD4 + large granular lymphocytic proliferations in which the clone specificity for hCMV peptides has been demonstrated. ${ }^{11,39}$ By contrast, Lima et al ${ }^{11}$ reported that CD8 + T-cell large granular lymphocytic proliferations in blood samples showed a pattern of $\mathrm{V} \beta$ distribution that mimics the frequency at which individual $\mathrm{V} \beta$ families are represented in normal CD8 + T cells, suggesting that CD8 + T-cell large granular lymphocytic leukemia cells were clonally transformed in a random manner. Overall, there is some evidence to encourage further evaluation of the TCR-V $\beta$ profile in a larger number of peripheral T-cell lymphoma cases.

In summary, TCR-V $\beta$ repertoire analysis in biopsy samples proved to be a highly specific and sensitive technique for peripheral T-cell lymphoma diagnosis when combined with conventional approaches. Once the $\mathrm{V} \beta$ family involved has been identified, it may also prove a promising tool for the assessment of bone marrow involvement, and for follow-up evaluation in blood or needle aspirates. Most interestingly, the precise identification of the T-cell clone allows accurate evaluation of its size and immunophenotype.

\section{Acknowledgements}

This work was supported by the Groupe Ouest Est d'Etude des Leucémies Aiguës et autres Maladies du Sang (GOELAMS), the Délégation Régionale à la Recherche Clinique et à l'Innovation of Grenoble University Hospital, the PHRC TENOMIC (co-investigators Prs Philippe Gaulard and Antoine Martin) and ARAMIS. We thank Ghislaine Del Vecchio, Richard Di Schiena, Michel Drouin, Frédérique Martinez and Christine Vallet very much for their efficient technical assistance. We also thank Dr Kheira Beldjord for her very helpful work in gene scanning analysis.

\section{Disclosure/conflict of interest}

The authors declare no conflict of interest.

\section{References}

1 Jaffe ES. Pathobiology of peripheral T-cell lymphomas. Hematol Am Soc Hematol Educ Program 2006;1: 317-322.

2 de Leval L, Gaulard P. Pathobiology and molecular profiling of peripheral T-cell lymphomas. Hematol Am Soc Hematol Educ Program 2008;1:272-279. 
3 Vose J, Armitage J, Weisenburger D. International peripheral T-cell and natural killer/T-cell lymphoma study: pathology findings and clinical outcomes. J Clin Oncol 2008;26:4124-4130.

4 Theodorou I, Delfau-Larue $\mathrm{MH}$, Bigorgne $\mathrm{C}$, et al. Cutaneous T-cell infiltrates: analysis of T-cell receptor gamma gene rearrangement by polymerase chain reaction and denaturing gradient gel electrophoresis. Blood 1995;86:305-310.

5 van Dongen JJ, Langerak AW, Bruggemann M, et al. Design and standardization of PCR primers and protocols for detection of clonal immunoglobulin and T-cell receptor gene recombinations in suspect lymphoproliferations: report of the BIOMED-2 Concerted Action BMH4-CT98-3936. Leukemia 2003;17: 2257-2317.

6 Bruggemann M, White H, Gaulard P, et al. Powerful strategy for polymerase chain reaction-based clonality assessment in T-cell malignancies. Report of the BIOMED-2 Concerted Action BHM4 CT98-3936. Leukemia 2007;21:215-221.

7 Theodorou I, Bigorgne C, Delfau $\mathrm{MH}$, et al. VJ rearrangements of the TCR gamma locus in peripheral T-cell lymphomas: analysis by polymerase chain reaction and denaturing gradient gel electrophoresis. J Pathol 1996;178:303-310.

8 Droese J, Langerak AW, Groenen PJ, et al. Validation of BIOMED-2 multiplex PCR tubes for detection of TCRB gene rearrangements in T-cell malignancies. Leukemia 2004;18:1531-1538.

9 Attygalle AD, Chuang SS, Diss TC, et al. Distinguishing angioimmunoblastic T-cell lymphoma from peripheral T-cell lymphoma, unspecified, using morphology, immunophenotype and molecular genetics. Histopathology 2007;50:498-508.

10 Cairns SM, Taylor JM, Gould PR, et al. Comparative evaluation of PCR-based methods for the assessment of $\mathrm{T}$ cell clonality in the diagnosis of $\mathrm{T}$ cell lymphoma. Pathology 2002;34:320-325.

11 Lima M, Almeida J, Santos AH, et al. Immunophenotypic analysis of the TCR-Vbeta repertoire in 98 persistent expansions of CD3(+)/TCR-alphabeta(+) large granular lymphocytes: utility in assessing clonality and insights into the pathogenesis of the disease. Am J Pathol 2001;159:1861-1868.

12 Feng B, Jorgensen JL, Jones D, et al. Flow cytometric detection of peripheral blood involvement by mycosis fungoides and Sezary syndrome using T-cell receptor Vbeta chain antibodies and its application in blood staging. Mod Pathol 2010;23:284-295.

13 Beck RC, Stahl S, O'Keefe CL, et al. Detection of mature T-cell leukemias by flow cytometry using antiT-cell receptor $\mathrm{V}$ beta antibodies. Am J Clin Pathol 2003;120:785-794.

14 Morice WG, Kimlinger T, Katzmann JA, et al. Flow cytometric assessment of TCR-Vbeta expression in the evaluation of peripheral blood involvement by T-cell lymphoproliferative disorders: a comparison with conventional T-cell immunophenotyping and molecular genetic techniques. Am J Clin Pathol 2004;121: 373-383.

15 Langerak AW, van Den Beemd R, Wolvers-Tettero IL, et al. Molecular and flow cytometric analysis of the Vbeta repertoire for clonality assessment in mature TCRalphabeta T-cell proliferations. Blood 2001;98:165-173.

16 Vonderheid EC, Boselli CM, Conroy M, et al. Evidence for restricted Vbeta usage in the leukemic phase of cutaneous T cell lymphoma. J Invest Dermatol 2005; 124:651-661.

17 Delfau-Larue $\mathrm{MH}$, Laroche $\mathrm{L}$, Wechsler J, et al. Diagnostic value of dominant T-cell clones in peripheral blood in 363 patients presenting consecutively with a clinical suspicion of cutaneous lymphoma. Blood 2000;96:2987-2992.

18 Posnett DN, Sinha R, Kabak S, et al. Clonal populations of $\mathrm{T}$ cells in normal elderly humans: the T cell equivalent to 'benign monoclonal gammapathy'. J Exp Med 1994;179:609-618.

19 Lima M, Teixeira Mdos A, Queiros ML, et al. Immunophenotype and TCR-Vbeta repertoire of peripheral blood T-cells in acute infectious mononucleosis. Blood Cells Mol Dis 2003;30:1-12.

20 Lin MT, Chang HM, Huang CJ, et al. Massive expansion of EBV+ monoclonal $\mathrm{T}$ cells with CD5 down regulation in EBV-associated haemophagocytic lymphohistiocytosis. J Clin Pathol 2007;60:101-103.

21 Salameire D, Le Bris Y, Fabre B, et al. Efficient characterization of the TCR repertoire in lymph nodes by flow cytometry. Cytometry A 2009;75:743-751.

22 Swerdlow SH, Campo E, Harris NL, et al. WHO Classification of Tumours of Haematopoietic and Lymphoid Tissues, 4th edn, vol 2. IARC: Lyon, 2008.

23 Jamal S, Picker LJ, Aquino DB, et al. Immunophenotypic analysis of peripheral T-cell neoplasms. A multiparameter flow cytometric approach. Am J Clin Pathol 2001;116:512-526.

24 Gorczyca W, Weisberger J, Liu Z, et al. An approach to diagnosis of T-cell lymphoproliferative disorders by flow cytometry. Cytometry 2002;50:177-190.

25 Weisberger J, Cornfield D, Gorczyca W, et al. Downregulation of pan-T-cell antigens, particularly CD7, in acute infectious mononucleosis. Am J Clin Pathol 2003;120:49-55.

26 Lee SS, Rudiger T, Odenwald T, et al. Angioimmunoblastic $\mathrm{T}$ cell lymphoma is derived from mature $\mathrm{T}$ helper cells with varying expression and loss of detectable CD4. Int J Cancer 2003;103:12-20.

27 Lefebvre C, Fabre B, Vettier C, et al. Composite splenic marginal zone lymphoma and mantle cell lymphoma arising from 2 independent B-cell clones. Hum Pathol 2007;38:660-667.

28 Delabesse E, Burtin ML, Millien C, et al. Rapid, multifluorescent TCRG Vgamma and Jgamma typing: application to T cell acute lymphoblastic leukemia and to the detection of minor clonal populations. Leukemia 2000;14:1143-1152.

29 Langerak AW, Molina TJ, Lavender FL, et al. Polymerase chain reaction-based clonality testing in tissue samples with reactive lymphoproliferations: usefulness and pitfalls. A report of the BIOMED-2 Concerted Action BMH4-CT98-3936. Leukemia 2007;21:222-229.

30 Derniame S, Vignaud JM, Faure GC, et al. Comparative T-cell oligoclonality in lung, tumor and lymph nodes in human non-small cell lung cancer. Oncol Rep 2005;13:509-515.

31 Ramzaoui S, Jouen-Beades F, Michot F, et al. Comparison of activation marker and TCR V beta gene product expression by CD4+ and CD8+ T cells in peripheral blood and lymph nodes from HIV-infected patients. Clin Exp Immunol 1995;99:182-188.

32 Tan BT, Warnke RA, Arber DA. The frequency of $B$ - and T-cell gene rearrangements and EpsteinBarr virus in T-cell lymphomas: a comparison between angioimmunoblastic T-cell lymphoma and peripheral 
T-cell lymphoma, unspecified with and without associated B-cell proliferations. J Mol Diagn 2006;8:466-475; quiz 527.

33 Geissinger E, Bonzheim I, Krenacs L, et al. Identification of the tumor cells in peripheral T-cell lymphomas by combined polymerase chain reaction-based T-cell receptor beta spectrotyping and immunohistological detection with $\mathrm{T}$-cell receptor beta chain variable region segment-specific antibodies. J Mol Diagn 2005;7:455-464.

34 Dummer R, Nestle FO, Niederer E, et al. Genotypic, phenotypic and functional analysis of CD4+CD7+ and CD4+CD7 - T lymphocyte subsets in Sezary syndrome. Arch Dermatol Res 1999;291:307-311.

35 Washington LT, Huh YO, Powers LC, et al. A stable aberrant immunophenotype characterizes nearly all cases of cutaneous T-cell lymphoma in blood and can be used to monitor response to therapy. BMC Clin Pathol 2002;2:5.

36 Koh HS, Lee C, Lee KS, et al. Twist2 regulates CD7 expression and galectin-1-induced apoptosis in mature T-cells. Mol Cells 2009;28:553-558.

37 Tembhare P, Yuan CM, Morris JC, et al. Flow cytometric immunophenotypic assessment of T-cell clonality by vbeta repertoire analysis in fine-needle aspirates and cerebrospinal fluid. Am J Clin Pathol 2010;137:220-226.

38 Dunleavy K, Wilson WH, Jaffe ES. Angioimmunoblastic T cell lymphoma: pathobiological insights and clinical implications. Curr Opin Hematol 2007;14:348-353.

39 Rodriguez-Caballero A, Garcia-Montero AC, Barcena P, et al. Expanded cells in monoclonal TCR-alphabeta+/ CD4+/NKa+/CD8-/+dim T-LGL lymphocytosis recognize hCMV antigens. Blood 2008;112:4609-4616.

Supplementary Information accompanies the paper on Modern Pathology website (http://www.nature.com/ modpathol) 